\title{
ROLE OF SUSPENDED PARTICULATE MATTER IN ANGIOGENESIS EMPLOYING CROWN GALL TUMOR ASSAY
}

\author{
SIMERPREET KAUR, JATINDER K. KATNORIA* \\ Department of Botanical and Environmental Sciences, Guru Nanak Dev Universtiy, Amritsar 143005, Punjab (India) \\ Email: jkat08@yahoo.com
}

Received: 28 Sep 2016 Revised and Accepted: 12 Nov 2016

\begin{abstract}
Objective: Aim of the study was to screen the suspended particulate matter for their role in enhancing angiogenesis employing crown gall tumor assay.

Methods: Particulate matter $\left(\mathrm{PM}_{10}\right)$ samples were collected, on glass fiber filter paper at the rate of $1.12-1.14 \mathrm{~m} 3 / \mathrm{min}$ for $8 \mathrm{hr}$ using high volume sampler, from six different sites of Amritsar city. Aqueous extracts of suspended particulate matter were prepared using a mechanical shaker for 24 hour and the filtrate was centrifuged and lyophilized.
\end{abstract}

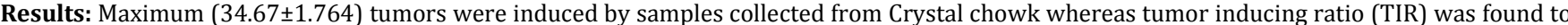
be comparably high for two sites viz., Crystal chowk and Bhandari bridge.

Conclusion: High tumor inducing ratio at the above-mentioned sites was correlated to high traffic emission from automobile exhaust. Crown gall tumor assay has been proved to be rapid, economical and reliable screening assay for angiogenesis agent.

Keywords: Particulate matter, Carcinogenicity, Tumor-inducing ratio

(C) 2017 The Authors. Published by Innovare Academic Sciences Pvt Ltd. This is an open access article under the CC BY license (http://creativecommons.org/licenses/by/4. 0/

DOI: http://dx.doi.org/10.22159/ijpps.2017v9i1.15440

\section{INTRODUCTION}

Diverse unambiguous carcinogens (classified as Group 1 by IARC) have been the major constituents of the outdoor air pollutants. There exists a wide range of variability in the concentrations of these pollutants, generally, due to their variable sources of generation, geographical location, time of year and weather conditions. The source of pollution can be of natural such windblown dust of particle from different countries, forest fires and volcanic eruptions or manmade such as fumes from vehicles tailpipe exhaust, smoke from burning fossil fuels. In the past decades, the disease burden due to air pollution has been found to be extensively increased affecting masses of people globally.

Exposure to ambient fine particles was reported to contribute 3.2 million premature deaths worldwide in 2010 mainly from cardiovascular disease (CVD) and 2,23, 000 deaths from lung cancer. It is estimated that more than half of the lung cancer deaths in China and other East Asian countries were solely attributable to ambient fine particulate matter [1]. World Health Organization (WHO) data and direct communication with national administrations estimated that over 2.5 billion people or $52 \%$ of the population in developing countries depend on biomass as their primary fuel for cooking and more than half of this population was found to be from three countries viz., India, China and Indonesia.

Annual Polycyclic aromatic hydrocarbon (PAH) emission from Asian countries was reported to be 2,90, 000 ton (55\% of the total) out of which China $(1,14,000$ ton per year) and India $(90,000$ ton per year) were the major contributors [2]. The organic fraction of particulate matter containing PAH metabolites had enhanced the cell proliferation through interaction with two major signalling pathways such as epidermal growth factor receptor pathway and the serine/threonine kinase Akt pathway [3]. Roy Choudhury [4] reported that women, in India, using biomass for cooking had up regulation of phosphorylated Akt proteins in airway epithelial cells, showing the risk of carcinogenesis via oxidative stress-mediated activation of the Akt signal transduction pathway as compared to women using liquefied petroleum gas (LPG). Burning of coal come out to be a stronger risk factor for lung cancer than wood burning [3,5-7] 3 billion people still cook and heat their homes using open fires, stoves burning biomass (wood, animal dung and crop waste) and coal.

Angiogenesis is a process involved proliferation of cell which leads to the growth of cell beyond their sizes using a continuous supply of nutrients from new blood vessels resulting in the development of tumours [8]. Epidemiological and clinical evidence have documented deleterious effects of air pollution on human health and its association with diseases, such as CVD [9-11]. Heavy traffic is one of the main causes of increase in the concentration of particulate matter which is supposed to be made up of DEPs. The population of motor vehicles in the world is expected to increase 1.3 billion by 2020 [12]. Various studies have revealed that for pulmonary effects, DEPs in the airways have some PAHs which enhanced pro-inflammatory and allergic responses. These responses are strongest for fine and ultrafine particulate air pollutants associated with DEP as one of the important components [13]. Considering all, the present work was planned to explore the role of suspended particulate matter in initiating tumorigenesis with the help of crown gall tumour assay.

\section{MATERIALS AND METHODS}

\section{Description of sampling area}

The importance of Amritsar location is enhanced by the fact that it is the wealthy and prosperous region with India's most auspicious temples and famous historical places. Amritsar (Punjab) is situated, in the north-west region of India and is about 32 miles east of Lahore, Pakistan. During the present study, samples were collected from six sites viz., Ram Bag (RB), Crystal chowk (CC), Railway Station (RS), Bhandari bridge (BB), Garden Colony (GC), Ranjit Avenue (RA) of Amritsar city during the winter season. Six sampling locations were selected on the basis of traffic load.

\section{Sampling procedure}

$\mathrm{PM}_{10}$ was collected on USEPA glass filter paper Type $\mathrm{A} / \mathrm{C}$ of pore size $1 \mu \mathrm{m}$; with a dimension of $20.3 \times 25.4 \mathrm{~cm}^{2}$ using High Volume Sampler (EnviroTech, APM 415) with constant flow rate $\left(1.2 \mathrm{~m}^{3} \mathrm{~min}\right.$ 1). The sampling was done over 8 hour period starting at $8.00 \mathrm{AM}$ and ending at 5.00 PM in the evening for three days. 18 samples were collected from six sites (three from each site). As per CPCB 
Guidelines, special attention was given to calibrate the machine some of the samples were also lost due to electrical failure as well as sampler malfunction during the sampling period.

\section{Sample extraction and analysis}

The particulate matter holding filter paper were cut into small pieces and put into a flask containing distilled water (DW). It was kept on a mechanical shaker for $24 \mathrm{~h}$ and was filtered through filter paper Whatmann No.1. The filtrate was collected and centrifuged at $5000 \mathrm{rpm}$ and the supernatant was collected. The collected supernatant was lyophilized. The lyophilized samples were redissolved in DMSO and were further diluted using distilled water to prepare different concentrations viz., 1, 25, 50, 75, 100, 250, 500 and $1000(\mathrm{ppm})$ to analyze effects of aqueous extracts of particulate matter in the initiation of tumors using Crown gall tumour inducing assay.

\section{Preparation of bacterial culture}

The strain of $A$. tumefaciens with MTCC No. 431 was purchased from IMTECH, Chandigarh. The lyophilized culture (powdered) was provided in the form of the ampoule. The ampoule was broken under the sterilised conditions, and the culture (powder) was poured to $25 \mathrm{ml}$ flask containing $12 \mathrm{ml}$ of nutrient broth. The flask was kept on a shaker for $18 \mathrm{~h}$ at a revolution of 180-225 rpm and temperature of $28^{\circ} \mathrm{C}$. The culture was poured to $2 \mathrm{ml}$ vials and was preserved in liquid nitrogen for future use. The culture from the frozen permanents was streaked on the nutrient plate and was kept in BOD incubator at $28^{\circ} \mathrm{C}$ for $24 \mathrm{~h}$. The culture plates were preserved in a refrigerator at $4{ }^{\circ} \mathrm{C}$ for future use. On the day of the experiment, a loopful of culture was taken with the help of inoculation needle and was poured to $25 \mathrm{ml}$ flask containing $12 \mathrm{ml}$ of nutrient broth. The flask was kept on a shaker for $18 \mathrm{~h}$ at 180-225 rpm and $28^{\circ} \mathrm{C}$. The solution was used as A. tumefaciens culture for further experiment.

Crown gall tumor inducing assay was performed according to the standard protocol with slight modification [14]. $50 \mu \mathrm{l}$ of a solution containing TSPM extract and A. tumefaciens culture (1: 1) was used for the experiment. Similarly, $50 \mu \mathrm{l}$ solutions containing $1 \mathrm{ppm}$ lead and $A$. tumefaceins (1: 1) was used as positive control while that of DW/DMSO and A. tumefaciens (1: 1) was used as negative control.

Disease-free potatoes (Solanum tuberosum L.) were purchased from Central Potato Research Institute (CPRI), Jalandhar, Punjab (India) washed under running tap water followed by distilled water, peeled off and then soaked in bleaching solution (10\%) for $20 \mathrm{~min}$. Potatoes were removed from the solution and were blotted on a sterile paper towel. A cylinder of tissue was taken from each potato by means of sterilised cork borer and $2 \mathrm{~cm}$ end of each tissue cylinder was discarded and remaining was cut into discs of uniform thickness $(0.5 \mathrm{~cm})$ by the aseptic cutter. Potatoes discs were dipped in a bleach solution (10\%) and were kept in the Laminar flow surface that was sterilised with $20 \%$ bleach solution. Petri plates were inoculated with potato discs submerged to $2 / 3 \mathrm{rd}$ from the base of agar plate carefully. $50 \mu$ of each solution as mentioned earlier were poured on each potato disc. Petri plate was covered with lid, parafilm tightly and kept in BOD incubator at $28^{\circ}-30^{\circ} \mathrm{C}$. On 17 th day, after staining with Lugol's dye (10\% KI, 5\% I2), discs were observed under a stereomicroscope (Model: Magnus MSZ-Bi: : Make: Olympus) at
$25 \mathrm{X}$ magnification to score a number of tumours. Frequency of tumor formation was calculated as

$$
\text { Tumor inducing ratio (TIR) }=\frac{\text { No. of tumors induced by sample }}{\text { No. of tumors in induced by control }}
$$

\section{Statistical analysis}

Results were represented as a mean and standard error. One way ANNOVA was applied for comparison of controls with test samples. $P$ value $\leq 0.05$ was considered for statistical significance.

\section{RESULTS AND DISCUSSION}

\section{Sensitivity test}

Sensitivity test of $A$. tumefaciens strain was tested to know the viability of strain against positive control $(\mathrm{Pb})$ before perusing for further experimentation. Results revealed significant variations between positive control and negative control (discs without treatment). Comparative study of positive control (PC) and disc treated with $A$. tumefaciens (OC) also exhibited significant variations as shown in fig. (1).

\section{Crown gall tumor assay}

Tumor assay carried out to evaluate effects of particulate matter extracts revealed a dose-dependent tumor activity in all the studied samples (table 1). The extracts of particulate matter collected from crystal chowk have shown the maximum tumor activity $(34.67 \pm 1.764)$ followed by Bhandari bridge $(33.00 \pm 2.517)$ in terms of a number of tumors at the highest concentration used $(1000 \mu \mathrm{g} / \mathrm{ml})$. Tumor-inducing ration (TIR) for these sites was observed to be 3.25 and 3.54, respectively (table 2). The tumor induction was found to be in the order of Crystal chowk $>$ Bhandari bridge $>$ Railway station $>$ Ram bag $>$ Ranjit avenue $>$ Garden colony. The tumor-inducing ratio was also found to be dosedependent manner as depicted in fig. 1. Tumor, not being a phenomenon of normal cells, is an abrupt proliferation of cells which disrupts the neighbouring cells [14]. During this process, excessive proliferation occurs because of continuous supply of nutrients through newly formed channels (blood vessels) and other growth factors resulting in rapid multiplication of tumor cells. However, during crown gall disease of potato, the growth of the tumor is supported via nutrient agar medium resulting in its marked progression. As cancer growth factors are leading challenge for emerging oncologist to combat with this problem, crown gall tumor assay was widely used for assessing anti-angiogenesis activities of several plants/plant products and has exhibited significant results [14-16] It is well documented that some tumorigenic mechanism are similar in plants and animals $[14,17]$.

During the present study, tumor-inducing effects of particulate matter extracts were studied. It was observed that the samples collected from Bhandari bridge and Crystal chowk had shown the significantly high tumor-inducing potential. Both these sites exposed to wide variety of activities including traffic emissions, open barbeques and restaurant chimney exhaust (using hearths) as well as personal experience to exposure of frequent prolonged traffic jams (comprising cars, scooters, diesel driven cars) due to narrow overbridge. Role of DEPs in the progression of angiogenesis was well documented [18]. The present study revealed that the assay used here can be explored in future for rapid screening of mutagens present in the environment due to its easy handling as compared to mammalian assays.

Table 1: Effects of total suspended particulate matter on induction of tumors following crown gall tumor assay

\begin{tabular}{|c|c|c|c|c|c|c|}
\hline \multirow[t]{2}{*}{ Conc. } & \multicolumn{6}{|c|}{ No. of tumors (mean \pm SE) } \\
\hline & RS & $\mathrm{CC}$ & BB & RB & GC & RA \\
\hline 1 & $1.00 \pm 0$ & $9.33 \pm 0.667$ & $5.00 \pm 0.577$ & $1.33 \pm 0.333$ & $1 \pm 0$ & $1.33 \pm 0.333$ \\
\hline 25 & $6.00 \pm 1.528$ & $10.67 \pm 0.333$ & $8.00 \pm 0.577$ & $3.67 \pm 0.333$ & $1.33 \pm 0.333$ & $2.33 \pm 0.882$ \\
\hline 50 & $9.33 \pm 0.882$ & $12.00 \pm 0.577$ & $12.67 \pm 1.202$ & $5.00 \pm 0.577$ & $1.33 \pm 0.333$ & $4.33 \pm 0.333$ \\
\hline 75 & $11.33 \pm 0.333$ & $14.67 \pm 1.453$ & $13.00 \pm 1.000$ & $6.33 \pm 0.882$ & $3.00 \pm 0.577$ & $5.00 \pm 0.577$ \\
\hline 100 & $14.67 \pm 1.453$ & $15.00 \pm 1.732$ & $15.33 \pm 0.882$ & $9.33 \pm 0.882$ & $4.33 \pm 0.882$ & $5.67 \pm 0.667$ \\
\hline 250 & $16.33 \pm 1.333$ & $22.67 \pm 0.882$ & $24.00 \pm 0.577$ & $12.33 \pm 0.882$ & $5.00 \pm 0.577$ & $7.00 \pm 0.577$ \\
\hline 500 & $20.67 \pm 2.186$ & $24.67 \pm 1.764$ & $28.33 \pm 1.453$ & $13 \pm 1.155$ & $6.33 \pm 0.333$ & $7.33 \pm 0.333$ \\
\hline 1000 & $27.33 \pm 1.202$ & $34.67 \pm 1.764$ & $33.00 \pm 2.517$ & $22 \pm 1.000$ & $7.00 \pm 0.577$ & $9.00 \pm 0.577$ \\
\hline $\mathrm{OC}$ & $12.67 \pm 1.202$ & $10.33 \pm 0.882$ & $9.33 \pm 0.882$ & $12.67 \pm 1.202$ & $10.67 \pm 0.880$ & $11.67 \pm 1.20$ \\
\hline $\mathrm{PC}$ & $24.00 \pm 1.732$ & $24.67 \pm 2.028$ & $20.33 \pm 1.856$ & $21.00 \pm 2.082$ & $21.67 \pm 1.760$ & $21.67 \pm 1.86$ \\
\hline F-ratio $(9,20)$ & $36.916 *$ & $39.257^{*}$ & $50.380 *$ & $44.062 *$ & $64.702 *$ & $45.512^{*}$ \\
\hline HSD & 6.680 & 6.700 & 6.510 & 5.254 & 3.880 & 4.322 \\
\hline
\end{tabular}

* represents significance level at p $\leq 0.05$, RS: Railway station; CC: Crystal Chowk; BB: Bhandari Chowk; RB: Ram Bag; GC: New Garden Colony; RA;

Railway avenue; OC: Only culture; PC: Positive control $\left[\mathrm{Pb}\left(\mathrm{C}_{2} \mathrm{H}_{3} \mathrm{O}_{2}\right)_{2}(1 \mathrm{ppm})\right.$ 
Table 2: Tumor-inducing ratio (TIR) of different concentrations of total suspended particulate matter following crown gall tumor assay

\begin{tabular}{|c|c|c|c|c|c|c|}
\hline \multirow[t]{2}{*}{ Conc. } & \multicolumn{6}{|c|}{ Tumor-inducing ratio } \\
\hline & RS & CC & BB & RB & GC & RA \\
\hline 1 & 0.07 & 0.88 & 0.54 & 0.10 & 0.09 & 0.11 \\
\hline 25 & 0.47 & 1.00 & 0.86 & 0.29 & 0.12 & 0.20 \\
\hline 50 & 0.74 & 1.13 & 1.36 & 0.39 & 0.13 & 0.37 \\
\hline 75 & 0.90 & 1.38 & 1.39 & 0.50 & 0.28 & 0.43 \\
\hline 100 & 1.16 & 1.41 & 1.64 & 0.73 & 0.41 & 0.49 \\
\hline 250 & 1.29 & 2.13 & 2.57 & 0.97 & 0.47 & 0.60 \\
\hline 500 & 1.63 & 2.31 & 3.04 & 1.02 & 0.59 & 0.63 \\
\hline 1000 & 2.16 & 3.25 & 3.54 & 1.73 & 0.66 & 0.77 \\
\hline OC & 1 & 1 & 1 & 1 & 1 & 1 \\
\hline PC & 1.90 & 2.31 & 2.18 & 1.66 & 2.03 & 1.86 \\
\hline
\end{tabular}

RS: Railway station; CC: Crystal Chowk; BB: Bhandari Chowk; RB: Ram Bag; GC: New Garden Colony; RA; Railway avenue; OC: Only culture; PC: Positive control $\left[\mathrm{Pb}\left(\mathrm{C}_{2} \mathrm{H}_{3} \mathrm{O}_{2}\right)_{2}(1 \mathrm{ppm})\right]$

Table 3: Characterization of tumor-inducing ratio (TIR)

\begin{tabular}{ll}
\hline Tumor-inducing ratio (TIR) & Characteristic \\
\hline $0-1$ & Non-toxic \\
$>1-2$ & Moderate toxic \\
$>2-3$ & Toxic \\
$>3$ & Highly toxic \\
\hline
\end{tabular}

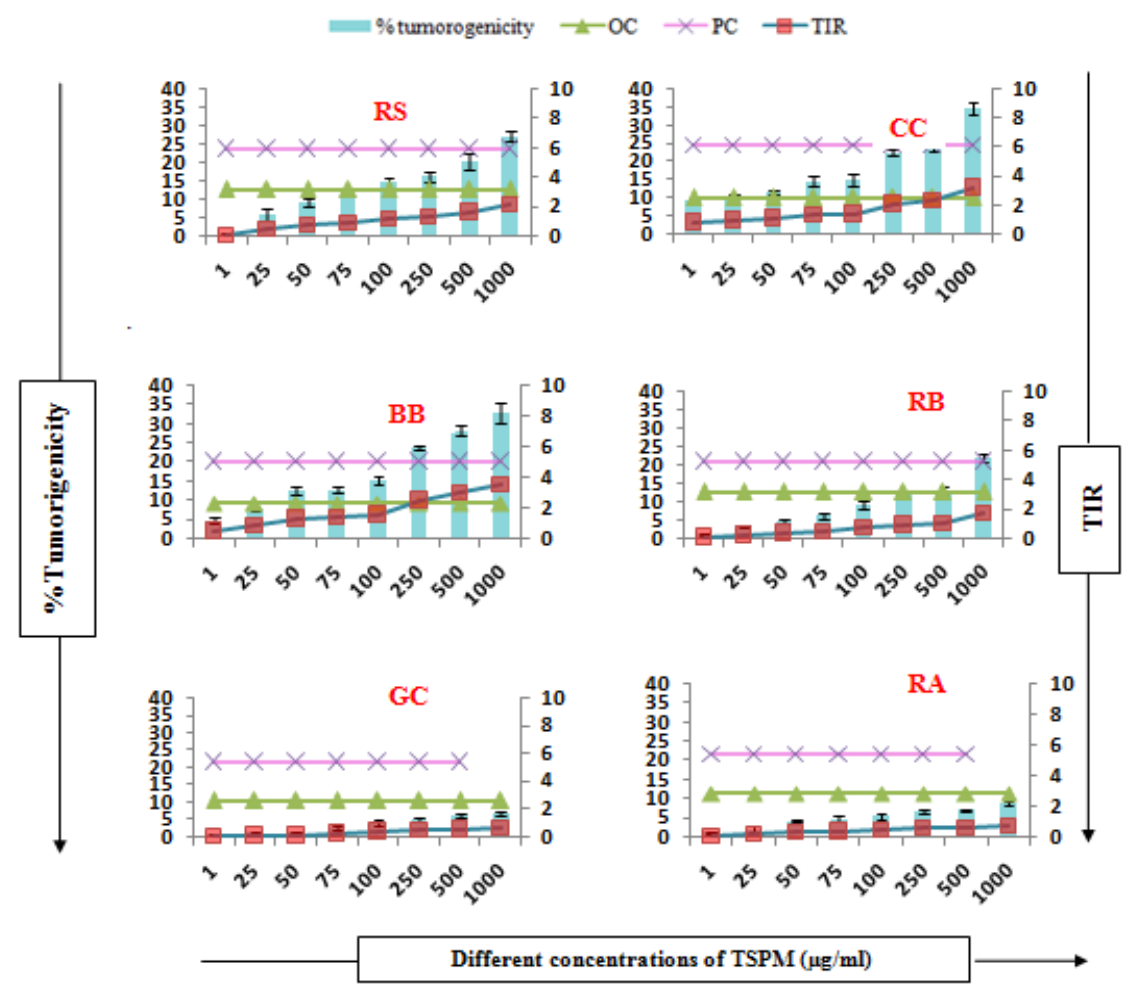

Fig. 1: Effects of suspended particulate matter on induction of tumors following crown gall tumor assay, RS: Railway station; CC: Crystal Chowk; BB: Bhandari Chowk; RB: Ram Bag; GC: New Garden Colony; RA; Railway Avenue; OC: Only culture; PC: Positive control

$\left[\mathrm{Pb}\left(\mathrm{C}_{2} \mathrm{H}_{3} \mathrm{O}_{2}\right)_{2}(1 \mathrm{ppm})\right] ;$ TIR: Tumor-inducing ratio
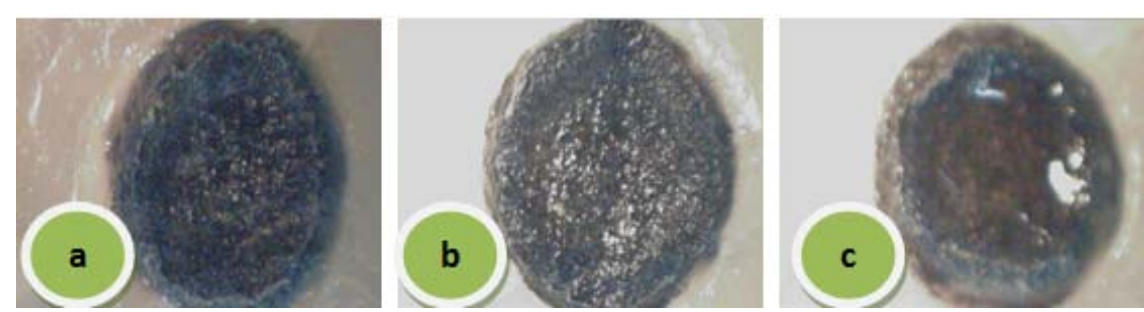

Potato discs untreated (a) in absence of Agrobacterium tumefaciens and treated with lead (b) and with particulate matter (c) in presence of Agrobacterium tumefaciens 

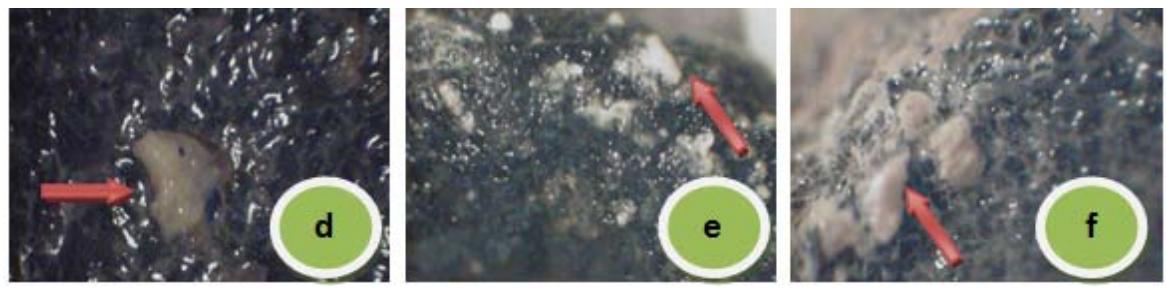

Potato discs treated with lead in the presence of Agrobacterium tumefaciens (d-f)
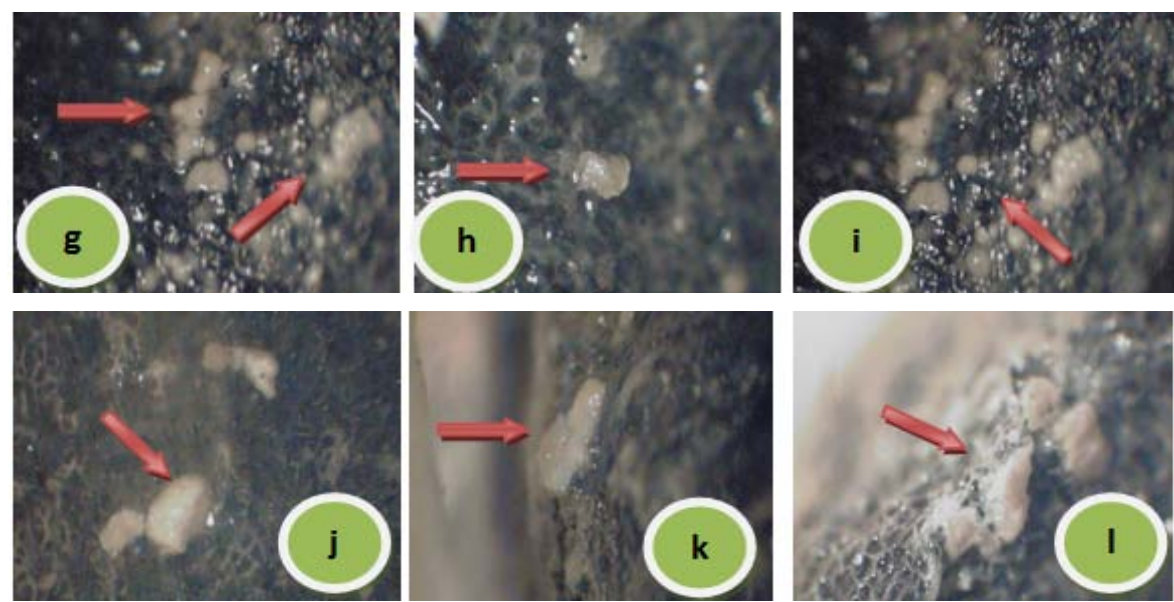

Fig. 2: Potato discs treated with aqueous extracts of suspended particulate matter in the presence of Agrobacterium tumefaciens (g-l)

\section{CONCLUSION}

Our findings indicate the promising role of particulate matter in tumor induction using crown gall tumor assay. This is the firsthand experiment exhibiting the effects of particulate matter in the progression of tumors using a plant bioassay. This assay has been proved to be useful in future studies to further isolate different mutagens/oncogenes/neoplastic molecules present in fractions of urban ambient air so that combating strategies should be formulated before occurring of any ambient episodic mortality.

\section{CONFLICTS OF INTERESTS}

\section{Declared none}

\section{REFERENCES}

1. Lim SS, Vos T, Flaxman AD, Danaei G, Shibuya K, Adair-Rohani H, et al. A comparative risk assessment of burden of disease and injury attributable to 67 risk factors and risk factor clusters in 21 regions, 1990-2010: a systematic analysis for the Global Burden of Disease Study 2010. Lancet 2012;380:2224-60.

2. Zhang Y, Tao S. Global atmospheric emission inventory of polycyclic aromatic hydrocarbons (PAHs) for 2004. Atmos Environ 2009;43:812-9.

3. Lim WY, Seow A. Biomass fuels and lung cancer. Respirol 2012;17:20-31.

4. Roychoudhury S, Mondal NK, Mukherjee S, Dutta A, Siddique S, Ray MR. Activation of protein kinase B (PKB/Akt) and risk of lung cancer among rural women in India who cook with biomass fuel. Toxicol Appl Pharmacol 2012;259:45-53.

5. IARC. Working Group on the Evaluation of Carcinogenic Risks to Humans Household use of solid fuels and high-temperature frying IARC. Monogr Eval Carcinog Risks Hum 2010;95:1-430.

6. Reid BC, Ghazarian AA, DeMarini DM, Sapkota A, Jack D, Lan Q, et al. Research opportunities for cancer associated with indoor air pollution from solid-fuel combustion. Environ Health Perspect 2012;120:1495-8.

7. Kurmi OP, Arya PH, Lam KB, Sorahan T, Ayres JG. Lung cancer risk and solid fuel smoke exposure: a systematic review and meta-analysis Eur Respir J 2012;40:1228-37.
8. Carmeliet P, Jain RK. Angiogenesis in cancer and other diseases. Nature 2000;407:249-57.

9. Brook RD, Franklin B, Cascio W, Hong Y, Howard G, Lipsett M, et al. Air pollution and cardiovascular disease a statement for healthcare professionals from the expert panel on population and prevention science. Am Heart Assoc Circulation 2004;109:2655-71.

10. Miller KA, Siscovick DS, Sheppard L, Shepherd K, Sullivan JH, Anderson GL, et al. Long-term exposure to air pollution and incidence of cardiovascular events in women. $\mathrm{N}$ Engl J Med 2007;356:447-58

11. Nemmar A, Hoylaerts MF Hoet, PH Nemery, B. Possible mechanisms of the cardiovascular effects of inhaled particles: systemic translocation and prothrombotic effects. Toxicol Lett 2004;149:243-53.

12. Sperling D, E Claussen. Motorizing the developing World. Access 2004;24:10-5.

13. Laden F, Neas LM, Dockery DW. Association of fine particulate matter from different sources with daily mortality in six US cities. Environ Health Perspect 2000;108:941-7.

14. Sarker MAQ, Mondol PC, Alam MJ, Parvez MS, Alam MF. Comparative study on antitumor activity of three pteridophytes ethanol extracts. J Agric Technol 2011;7:1661-71.

15. Ahmad S, Ullah F, Ayaz M, Zeb A, Ullah F, Sadiq A. Antitumor and antiangiogenic potentials of isolated crude saponins and various fractions of Rumex hastatus D Don. Biol Res 2016;49:1-9.

16. Galsky AG, Wilsey JP. Crown gall tumor disc bioassay a possible aid in the detection of compounds with antitumor activity. Plant Physiol 1980;65:184-5.

17. Braun A. The relevance of plant tumor systems to an understanding of the basic cellular mechanisms underlying tumorigenesis. Progress Exp Tumor Res 1971;15:165-87.

18. Xu X, Kherada N, Hong X, Quan C, Zheng L, Wang A, et al. Diesel exhaust exposure induces angiogenesis. Toxicol Lett 2009;191:57-68.

\section{How to cite this article}

- $\quad$ Simerpreet Kaur, Jatinder K Katnoria. The role of suspended particulate matter in angiogenesis employing crown gall tumor assay. Int J Pharm Pharm Sci 2017;9(1):34-37. 